\title{
Study of association of preoperative glycosylated haemoglobin level and outcome after cardiac surgery
}

\author{
Harshil Joshi $^{1}$, Vijaya Kumara ${ }^{1 *}$, Guruprasad Rai ${ }^{2}$, Aravind Kumar Bishnoi ${ }^{3}$ \\ Assistant Professor ${ }^{1}$, Department of Anaesthesiology, Assistant Professor ${ }^{2}$, Professor $^{3}$, \\ Department of Cardiovascular and Thoracic Surgery, Kasturba Medical Collage \\ Manipal, Udupi, Karnataka - 576104, India.
}

\begin{abstract}
Background: Diabetes mellitus involves $8.7 \%$ of the adult community in India, and its preponderance is rising. Diabetes is an independent risk factor for complications after open cardiac surgery. Poor glycaemic control, measured by glycosylated haemoglobin $\mathrm{A}_{1 \mathrm{C}}\left(\mathrm{HbA}_{\mathrm{lc}}\right)$, is associated with high incidence of micro and macroangiopathy. HbAlc reflects the patient's prevailing sugar control over the previous 120-150 days. Perioperative cardiac surgical risk scoring systems like Euro Score and STS scoring systems do not include HbAlc level as risk factor. We intended to study the correlation of preoperative HbAlc level and outcome after cardiac surgery.
\end{abstract}

Methodology: A total of 350 patients who had undergone elective cardiac surgery were included. All patients were stratified into two groups, Group 1 with $\mathrm{HbA}_{1 \mathrm{c}}$ level $<7 \%$, Group $2>7 \%$. Intraoperative and postoperative adverse events were documented retrospectively. The two groups of patients were compared with regard to their demographic data, operation risk, mortality and morbidity.

Results: Overall incidence of major adverse events $(7.7 \%)$ and mortality $(4.8 \%)$ were very low. Incidence of sternal wound infection and prolonged ventilator support $(>24 \mathrm{hrs})$ were significant in group 2 compared to group 1 ( $\mathrm{p}$ values were 0.03 and 0.01 respectively).

Conclusion: Preoperative HbAlc level may provide more accurate prognostic information about outcomes after all major open cardiac surgeries compared with a diabetes status alone.

Keywords: Glycosylated haemoglobin (HbAlc); cardiac surgery; post-operative complications; diabetes mellitus; glycaemia control

\section{Introduction}

Diabetes mellitus affects $8.7 \%$ of the adult community in India, and its preponderance is rising. ${ }^{1}$ Diabetes is an independent risk factor for complications after cardiac surgery. Poor glycaemic control, measured by glycosylated haemoglobin $\mathrm{A}_{1 \mathrm{C}}\left(\mathrm{Hb}_{1 \mathrm{c}}\right)$, is associated with high incidence of micro and macroangiopathy. ${ }^{1}$ Glucose in the blood binds to haemoglobin irreversibly to form a stable $\mathrm{HbA} 1 \mathrm{c}$ complex. It
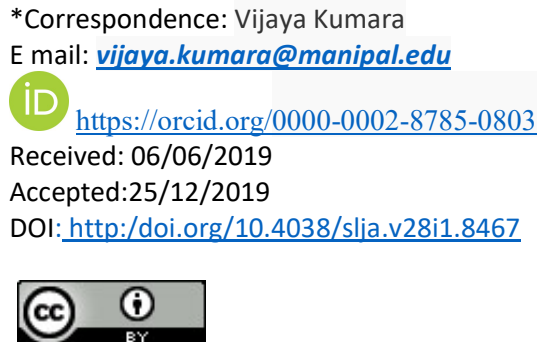

illustrates the patient's prevailing sugar control over the past $120-150$ days. $\mathrm{HbA}_{1 \mathrm{c}}$ may be underestimated in few circumstances like haemolytic anaemia, chronic renal failure, and in patients who are on certain medications. (e.g. erythropoietin, iron and vitamin $\mathrm{B}_{12}$ preparations). ${ }^{2}$ The level of $\mathrm{HbA}_{1 \mathrm{c}}$ may be falsely increased due to hypertriglyceridaemia, hyperbilirubinaemia, alcoholism, previous splenectomy, pregnancy, and medications (e.g. opiates, vitamin $\mathrm{C}$, salicylates). ${ }^{2} \mathrm{HbA} 1 \mathrm{c}$ levels less than $7 \%$ are recommended by The American Diabetes Association a (ADA) and this is associated with reduced risk of complications related to diabetes mellitus. ${ }^{3}$ Euro SCORE and American STS SCORE do include diabetes in the risk factors, ${ }^{4,5}$ but $\mathrm{HbAlc}$ level is not included as a risk indicator for cardiac surgery in any of the above mentioned preoperative risk scores. 


\section{Methodology}

Hospital Research Ethics Committee approval was obtained. Permission from Medical superintendent was obtained to access medical records and confidentiality was ensured by the use of indirect identifiers. Data of all patients who had undergone elective cardiac surgery (MVR, AVR, CABG, and DVR) was obtained from the hospital records section.

Study design: Data of all patients who had undergone elective cardiac surgery (MVR, • AVR, CABG, and DVR) were included in the study. Patients who had undergone emergency cardiac surgeries, paediatric cardiac surgeries, and those with multiple comorbidities like severe renal, hepatic and CNS abnormalities (stroke, CKD stage 5 etc.) were excluded from the study. All patients were stratified into two groups, depending on their preoperative $\mathrm{HbAlc}$, Group 1 with HBA1C level $<7 \%$, and group 2 with level $>7 \%$.

Anaesthesia technique: All patients were given general anaesthesia with intravenous induction with fentanyl, propofol, midazolam and ${ }^{\bullet}$ vecuronium. Anaesthesia was maintained with ${ }^{\bullet}$ inhalation agent isoflurane and fentanyl bolus doses. Haemodynamic monitoring was done with radial arterial and central venous lines. All patients received intravenous antifibrinolytic agent (tranexamic acid 1g) before skin incision. All surgeries were done with midline sternotomy incision. Anticoagulation was achieved with intravenous heparin. In the off pump coronary artery bypass (OPCAB) patients, 150-200 IU/kg of heparin was administered before division of the internal mammary artery (IMA) to maintain an activated clotting time (ACT) between 250350 seconds. Anticoagulation was reversed with protamine $1 \mathrm{mg} / 100 \mathrm{IU}$ of heparin on completion of all anastomoses. In on pump cases (valves and combined valve and CABG), 300-400 $\mathrm{IU} / \mathrm{kg}$ of heparin was given to target an ACT of at least 480 seconds before the commencement of cardiopulmonary bypass (CPB). Anticoagulation was reversed with protamine 3$4 \mathrm{mg} / 100 \mathrm{IU}$ of heparin dose on termination of CPB. Intraoperative hyperglycaemia was managed with continuous insulin infusion to maintain target sugar level between $120 \mathrm{mg} / \mathrm{dl}$ to $180 \mathrm{mg} / \mathrm{dl}$. Postoperative glycaemic control was managed with either continuous infusion or subcutaneous boluses according to sliding scale.
Intraoperative and postoperative adverse events were recorded from hospital data. Complications like arrhythmias, cerebrovascular accidents, bleeding, renal dysfunction, perioperative myocardial ischaemia, etc. were documented. The two groups of patients were analyzed concerning their demographic data, surgical risk, mortality, and morbidity. Following are the outcomes of cardiac surgery considered.

Primary outcomes:

Death within six days of surgery

Cardiac adverse events like new onset ST changes and arrhythmias, requiring more than two inotropes and the use of an intra-aortic balloon pump (IABP).

Stroke or transient ischaemic attack (TIA)

Post-operative renal dysfunction requiring dialysis

Prolonged mechanical ventilation (more than 24 hours)

- Re-exploration

Secondary outcomes:

Length of hospital stay.

Sternal wound infection

\section{Statistical analysis}

All quantitative data were coded and transformed into an excel master sheet for computer programming. A chi-square test was used to evaluate categorical variables for analysis. For all practical analyses, $\mathrm{p}<0.05$ was accepted to be statistically significant. Statistical analysis of the data was done using SPSS (version 16) package.

\section{Results}

A total of 350 patients who underwent elective cardiac surgery from November 2017 to October 2018 in our hospital were analyzed in this study (219 patients with HbAlc $<7 \%$, 131 patients with HbAlc level $>7 \%$ ). Preoperative demographics, clinical variables, and perioperative factors comparing patients with two groups are listed in Table 1. Sixty seven (30.59\%) patients in group 1 were diabetic with HbA1c levels $<7 \%$. In group two, 101 (77\%) patients were known diabetics. Number of patients with severe LV dysfunction were considerably high in group two (11.4\%) compared to group 1 (1.3\%) (P value 0.03$)$ 
Table 1: Comparison of preoperative demographics, clinical variables and perioperative factors

\begin{tabular}{|l|l|l|l|}
\hline Risk & HbAlc $<7.0 \%$ & HbA1c $>7 \%$ & P value \\
\hline TOTAL (n) & $219(62.57 \%)$ & $131(47.24 \%)$ & \\
\hline Mean Age (yrs.) & 58 & 63 & 0.09 \\
\hline \multirow{2}{*}{ Sex } & M-141(64.38\%) & $84(64.12 \%)$ & 0.13 \\
\cline { 2 - 4 } & F- 78(35.62\%) & $47(35.87 \%)$ & 0.22 \\
\hline $\begin{array}{l}\text { Diabetes } \\
\text { Mellitus }\end{array}$ & $67(30.59 \%)$ & $101(77.09 \%)$ & 0.001 \\
\hline Hypertension & $94(42.95 \%)$ & $78(59.54 \%)$ & 0.05 \\
\hline CABG & $140(63.92 \%)$ & $92(70.22 \%)$ & 0.56 \\
\hline MVR & $30(13.69 \%)$ & $14(10.68 \%)$ & 0.62 \\
\hline AVR & $10(4.56 \%)$ & $5(3.81 \%)$ & 0.11 \\
\hline CABG \pm MVR & $3(1.36 \%)$ & $10(7.63 \%)$ & 0.006 \\
\hline CABG \pm AVR & $6(2.73 \%)$ & $3(2.29 \%)$ & 0.44 \\
\hline DVR & $9(4.10 \%)$ & $6(4.58 \%)$ & 0.24 \\
\hline Others & $21(9.58 \%)$ & $1(0.76 \%)$ & 0.72 \\
\hline LMCA & $44(31.20 \%)$ & $33(25.19 \%)$ & 0.35 \\
\hline \multirow{2}{*}{$\begin{array}{l}\text { EF } \geq 50 \%-50 \\
\leq 35\end{array}$} & $181(82.64 \%)$ & $104(79.38 \%)$ & 0.32 \\
\cline { 2 - 4 } & $35(15.98 \%)$ & $12(9.16 \%)$ & 0.88 \\
\cline { 2 - 4 } & $3(1.38 \%)$ & $15(11.45 \%)$ & 0.03 \\
\hline Arrhythmias & $31(14.15 \%)$ & $36(27.48 \%)$ & 0.11 \\
\hline CPB & $79(36.07 \%)$ & $39(29.77 \%)$ & 0.61 \\
\hline
\end{tabular}

In-hospital outcomes are summarized by $\mathrm{HbA1c}$ subgroup in Table 2. For all the patients, the overall incidence of mortality was low (4.8\%). Incidence of sternal wound infections and prolonged mechanical ventilation were significant in group $2(2.29 \%$ and $20.6 \%$ respectively) compared to group $1(0.45 \%$ and $8.2 \%$ respectively) ( $\mathrm{P}$ value 0.03 and 0.01 respectively). Incidence of CVA ( $p$ value-0.52), renal failure ( $\mathrm{p}$ value-0.06), re-exploration $(\mathrm{p}$ value- 0.59 ) and length of hospital ( $p$ value0.15 ) stay were not statistically significant in both the groups. There was only one incidence of VAP found in group 2.

Table 2: In-hospital outcomes for all patients by $\mathrm{HbAlc}$ risk group

\begin{tabular}{|l|l|l|l|}
\hline Outcome & $\begin{array}{l}\text { HbA1c }< \\
7.0 \% \mathrm{n}=219\end{array}$ & $\begin{array}{l}\text { HbA1c } \\
>7.0 \% \mathrm{n}= \\
131\end{array}$ & P value \\
\hline Death & $9(4.10 \%)$ & $8(6.1 \%)$ & 0.17 \\
\hline Renal failure & $2(0.91 \%)$ & $4(3.05 \%)$ & 0.06 \\
\hline CVA & $2(0.91 \%)$ & $3(2.29 \%)$ & 0.52 \\
\hline Cardiac accidents & $4(1.82 \%)$ & $5(3.8 \%)$ & 0.06 \\
\hline Infection(DSWI) & $1(0.45 \%)$ & $3(2.29 \%)$ & 0.03 \\
\hline $\begin{array}{l}\text { Prolonged ventilation } \\
\geq 24 \text { hrs. }\end{array}$ & $18(8.21 \%)$ & $27(20.61 \%)$ & 0.01 \\
\hline Re-exploration & $2(0.91 \%)$ & $3(2.29 \%)$ & 0.59 \\
\hline Re intubation & $3(1.36 \%)$ & $4(3.05 \%)$ & 0.07 \\
\hline VAP & 0 & $1(0.7 \%)$ & \\
\hline Tracheostomy & $2(0.91 \%)$ & $1(0.7 \%)$ & 0.83 \\
\hline $\begin{array}{l}\text { Length of Hospital } \\
\text { stay(mean) in days }\end{array}$ & 5.8 & 6.3 & 0.15 \\
\hline
\end{tabular}

Perioperative adverse events in $\mathrm{HbA1c}$ subgroups is analyzed in Table 3 . Requirement of IABP, unplanned CPB, blood transfusion requirement, new onset ST changes and mortality were compared. The study showed no significant difference in two groups concerning the above events.

Table 3: Perioperative events in all patients by $\mathrm{HbA1c}$ risk group

\begin{tabular}{|l|l|l|l|}
\hline Events & $\begin{array}{l}\text { HbA1c }<7.0 \% \\
\mathrm{n}=219\end{array}$ & $\begin{array}{l}\text { HbA1c }>7.0 \% \\
\mathrm{n}=131\end{array}$ & P value \\
\hline Arrhythmias & $78(35.61 \%)$ & $46(35.11 \%)$ & 0.57 \\
\hline Transfusion & $44(20.09 \%)$ & $29(22.13 \%)$ & 0.77 \\
\hline $\begin{array}{l}\text { New onset ST } \\
\text { changes }\end{array}$ & $12(5.47 \%)$ & $10(7.63 \%)$ & 0.35 \\
\hline Inotropes $\geq 2$ & $88(40.18 \%)$ & $56(42.74 \%)$ & 0.26 \\
\hline $\begin{array}{l}\text { Unplanned } \\
\text { CPB }\end{array}$ & $1(0.45 \%)$ & $2(1.52 \%)$ & 0.55 \\
\hline IABP & $6(2.73 \%)$ & $9(6.87 \%)$ & 0.61 \\
\hline Deaths & $9(4.10 \%)$ & $8(6.1 \%)$ & 0.17 \\
\hline
\end{tabular}

\section{Discussion}

The majority of adult cardiac surgeries are CABGs, involving elderly patients with multiple comorbidities. Diabetes and hypertension are the known risk factors for coronary artery disease. Commonly, diabetes is diagnosed when the patient comes for CABG surgery. In the present study, we retrospectively evaluated 350 patients undergoing elective cardiac surgeries. Overall in-hospital mortality in all patients was $4.8 \%$. In our study, 168 patients of 350 had diabetes. In patients with HBA1c $>7 \%, 77 \%$ of patients had diabetes and $23 \%$ of patients were undiagnosed diabetics, and they were not on any hypoglycaemic medication. Many studies, which compared diabetic and non-diabetic patients after coronary revascularization surgery have generated conflicting results. ${ }^{5,6}$ Calafiore and colleagues, in their study proved that diabetes mellitus was an independent risk factor for early cardiac mortality and morbidity. ${ }^{5}$ Rajakaruna et al, found comparable mortality outcomes in diabetic and non-diabetic patients. ${ }^{6}$ Study done by Kubal et al reported that diabetic patients who were on insulin had increased postoperative complications than the patients who had mere history of diabetes. ${ }^{7}$ The study done by Carson and colleagues compared outcomes in 41,663 diabetic patients with $1,05,123$ non diabetic patients and found a near $30 \%$ increase in overall complications rate in diabetic patients compared non-diabetic patients. ${ }^{8}$ Furnary and colleagues, reported that glycaemic control by continuous insulin infusion in perioperative period reduced mortality and infection rate 
among diabetic patients. ${ }^{9,10} \mathrm{We}$ aimed to regulate glucose level between $120 \mathrm{mg} / \mathrm{dl}$ to $180 \mathrm{mg} / \mathrm{dl}$ in all the diabetic patients throughout perioperative period using continuous insulin infusion or bolus doses of insulin according to sliding scale. Once patients transferred post-operative intensive care unit, management was variable and dependent on their sugar level in the intensive care unit. Preoperative HbAlc level still emerged as an independent predictor of mortality and wound infection after CABG in the multivariate analysis, even after adjusting for mean glucose levels on the day of surgery and the first three postoperative days. ${ }^{11}$

In the present study, we sought to determine whether these outcome differences could be explained by preoperative glycaemic control as measured by $\mathrm{HbA} 1 \mathrm{c}$ rather than the mere history of diabetes mellitus. We agree with previous authors that strict intraoperative and postoperative glucose control is imperative to minimize postoperative morbidity and mortality after any open cardiac surgery. However, it is plausible from these data that $\mathrm{HbA1c}$ is also an independent predictor of postoperative adverse events that is not entirely due to intra and postoperative glucose control. It may be challenging to achieve intra and postoperative euglycaemia in patients with elevated HbAlc. Therefore, more aggressive glucose management should be used in these patients in the perioperative period. Current guidelines according to the American Diabetes Association recommend HbAlc screening of diabetic patients as frequently as every three months in patients with elevated HbA1c levels $(>7 \%)$ or in patients with medication adjustments to ensure an adequate treatment regimen. ${ }^{12}$

Current recommendations suggest that patients with diabetes aim to achieve HbAlc levels of at least less than $7 \%$.We chose to order HbAlc for all patients to determine whether this approach would identify patients who had uncontrolled hyperglycaemia without a previous diagnosis of diabetes mellitus. ${ }^{13,14}$ It is possible that a preoperative HbAlc level may provide more accurate prognostic information about outcomes after all major open cardiac surgeries compared with a diabetes status alone.

\section{Conclusion}

Our study showed that elevated preoperative HbAlc levels are associated with a significant increase in sternal wound infection and prolonged mechanical ventilator support in patients undergoing elective cardiac surgery. A preoperative HbAlc level may provide more accurate prognostic information about outcomes after all major open cardiac surgeries compared with a diabetes status alone.

\section{Limitations}

The limitations in this study include, it was a retrospective, descriptive in nature, and a small cohort size. It is difficult to correlate all adverse outcomes on HbAlc levels by only one study. More prospective randomized long-term studies must be designed to study the adverse perioperative outcomes of diabetes in terms of preoperative HbA1c levels.

\section{Acknowledgment}

The writer would like to express their acknowledgment to the Hospital Records Department for providing access to case reports.

\section{References}

1. UK Prospective Diabetes Study Group. Tight blood pressure control and risk of macro vascular and micro vascular complications in type 2 diabetes (UKPDS 38) BMJ. 1998; 317:703-713. https://doi.org/10.1136/bmj.317.7160.703 PMCid:PMC28659

2. Reynolds TM, Smellie WS, Twomey PJ. Glycated hemoglobin (HbAlc) monitoring. BMJ 2006; 333: 586-588.

3. American Diabetes Association. Standards of medical care in diabetes. Diabetes Care. 2005; 28:S4-36. https://doi.org/10.2337/diacare.28.suppl_1.S4

4. Roques F, Michel P, Goldstone AR. The logistic Euro SCORE. Eur Heart J 2003;24: 882-883 https://doi.org/10.1016/S0195-668X(02)00799-6

5. Calafiore AM, Di Mauro M, Di Giammarco G et al. Effect of diabetes on early and late survival after isolated first coronary bypass surgery in multivessel disease. J Thorac Cardiovasc Surg. 2003; 125:144-54. https://doi.org/10.1067/mtc.2003.73

PMid:12538998

6. Rajakaruna C, Rogers CA, Suranimala C et al. The effect of diabetes mellitus on patients undergoing coronary surgery: a risk adjusted analysis. J Thorac Cardiovasc Surg. 2006; 132:802-10.

https://doi.org/10.1016/j.jtcvs.2006.05.056 PMid:17000291

7. Kubal C, Srinivasan AK, Grayson AD et al. Effect of risk-adjusted diabetes on mortality and morbidity after coronary artery bypass surgery. 
Kumara et al. Sri Lankan Journal of Anaesthesiology: 28(1):14-18 (2020)

Ann Thorac Surg. 2005; 79:1570-6. https://doi.org/10.1016/j.athoracsur.2004.10.035 PMid:15854935

8. Carson JL, Scholz PM, Chen AY et al. Diabetes mellitus increases short-term mortality and morbidity in patients undergoing coronary artery bypass graft surgery. J Am Coll Cardiol. 2002; 40:418-23.

https://doi.org/10.1016/S0735-1097(02)01969-1

9. Furnary AP, Gao G, Grunkemeier GL et al. Continuous insulin infusion reduces mortality in patients with diabetes undergoing coronary artery bypass grafting. J Thorac Cardiovasc Surg.2003;125:1007-21

https://doi.org/10.1067/mtc.2003.181 PMid:12771873

10. Furnary AP, Zerr KJ, Grunkemeier GL et al. Continuous intravenous insulin infusion reduces the incidence of deep sternal wound infection in diabetic patients after cardiac surgical procedures. Ann Thorac Surg. 1999; 67:352-62. https://doi.org/10.1016/S0003-4975(99)00014-4

11. Lazar HL, Chipkin S, Philippides G et al. Glucose-insulinpotassium solutions improve outcomes in diabetics who have coronary artery operations. Ann Thorac Surg. 2000;70:145-50 https://doi.org/10.1016/S0003-4975(00)01317-5

12. UK Prospective Diabetes Study (UKPDS) group. Intensive blood-glucose control with sulphonylureas or insulin compared with conventional treatment and risk of complications in patients with type 2 diabetes (UKPDS 33). Lancet.1998;352:837-53.

https://doi.org/10.1016/S0140-6736(98)07019-6

13. The ACE/ADA Task Force on Inpatient Diabetes. American College of Endocrinology and American Diabetes Association Consensus Statement on inpatient diabetes and glycemic control. Diabetes Care. 2006; 29:1955-62. https://doi.org/10.2337/dc06-9913

PMid:16873812

14. Halkos, M. E., Puskas, J. D., Lattouf, O. M. Elevated preoperative hemoglobin A1C level is predictive of adverse events after coronary artery bypass surgery. The Journal of thoracic and cardiovascular surgery, 2008; 136(3), 631-640. https://doi.org/10.1016/j.jtcvs.2008.02.091

PMid:18805264 